\title{
Enhancement of a High Speed De-Excitation System for Brushless Synchronous Machines by large blocking voltagesemiconductors
}

\author{
C. A. Platero, F. Blázquez, E. Rebollo, F.R. Blánquez, J.A. Martínez and M. Redondo.
}

\begin{abstract}
One of the main disadvantage of the synchronous machines with brushless excitation is that the field winding is not accessible for the de-excitation. The de-excitation process is very slow as the field current flows through the rotating diodes which operate in freewheel mode. Therefore in case of an internal fault, despite the correct operation of the protection relays, the machine could have severe damages. A high-speed de-excitation system for these machines was developed. The deexcitation is achieved by inserting a resistance in the field circuit by a static switch semiconductor based, obtaining a dynamic response similar to that achieved in machines with static excitation. This paper presents the improvement in the de-excitation system in the second commercial 20 MVA hydro generator in operation. In this case, high blocking voltage semiconductor was used, making the dynamic response even better, than in the first hydro generator.
\end{abstract}

Index Terms - Synchronous generator excitation; AC generator excitation; Brushless rotating machines; Synchronous machines

\section{NOMENCLATURE}

$R_{f} \quad$ Resistance of the rotor winding.

$L_{f} \quad$ Inductance of the rotor winding.

$M_{f} \quad$ Rotor-statorcoupling.

$L_{d} \quad$ Direct axis synchronous inductance.

$T_{d} \quad$ Rotor load time constant.

$T_{d 0}^{\prime} \quad$ Rotor un-load time constant.

$R_{d} \quad$ Discharge resistor of the main generator.

If exc Excitation current of the exciter.

$I_{f} \quad$ Rotor current of the main generator.

$U_{\text {gen }} \quad$ Main generator stator voltage.

Time constant

$U_{f} \quad$ Rotor voltage of the main generator.

$U_{\text {diode }} \quad$ Rotating diode bridge voltage

$U_{R} \quad$ Discharge resistor voltage

$U_{C E} \quad$ Collector emitter voltage

$U_{\text {CEmax }}$ Blocking voltage

$I_{r} \quad$ Discharge resistor current.

$R_{d} \quad$ Discharge resistor of the main generator.

$R_{d \text { exc }} \quad$ Discharge resistor of the exciter.

\section{INTRODUCTION}

$\mathrm{S}$ YNCHRONOUS machines use protection relays in order to protect them against short circuits, overloads and, in general, abnormal operations or faults that could be dangerous to the power facilities and the operators. For that purpose there are minimum requirements for obtaining adequate protection in the event of faults or abnormal operation [1]. There are many specific protection to protect different parts of the machine, such as the rotor windings and the rotating diodes, for which schemes have been developed [2]-[3].

In case of internal fault the generator breaker should be opened to eliminate the power system contribution to the fault. These faults cannot be switched off by merely tripping the generator breaker, as it is therefore important to reduce as quickly as possible the source voltage that is driving the fault current supplied by the generator itself. So a rapid deexcitation of the synchronous machine is necessary to limit any possible damage.

The aim of the field suppression system is accelerate the field current decrease in the rotor winding. If the voltage of the field winding is reduced to zero, the current will decrease in accordance with the natural time constant of the field winding. After the trip of the generator breaker, with no current in the armature windings, the time constant depends on the field winding impedance $\left(\mathrm{R}_{\mathrm{f}}, \mathrm{L}_{\mathrm{f}}\right)$. This time constant is too large and de-excitation process will take several seconds.

In order to accelerate the de-excitation it is a normal practice to insert an additional resistor. This resistor, known as a discharge resistor, which converts the magnetic field 
energy into heat.

Some generator makers use non-linear discharge resistors combined to the negative voltage injection, which produce even faster de-excitations [4]. Another new technique combines a non-linear resistor, a capacitor and a diode [5].

All these techniques can be used in machines with static excitation systems, where there are brushes and the field winding can be accessed.

Nevertheless, in synchronous machine with ac exciters and rotating diodes where there are no brushes, called brushless, the rotor cannot be accessed. So the de-excitation time constant cannot be reduced.

A novel high-speed de-excitation system for brushless synchronous machine was developed [6]. This new system was validated by computer simulations and experimental laboratory tests using a special $5 \mathrm{kVA}$ laboratory synchronous machine [7]. After numerous tests, this deexcitation system was successfully commissioned in a large size 15 MVA laboratory synchronous brushless generator place in Bilbao Alstom factory [8].

The first 20 MVA commercial hydro generator with this de-excitation system was put in operation in September 2013. In this brushless generator the de-excitation constant was reduced four times.

This paper presents the improvements in the second unit of the power plant which is a 20 MVA hydro generator. In this case the non-load de-excitation time constant is reduced from $4 \mathrm{~s}$ to $0,47 \mathrm{~s}$. This reduction is achieved by the use of larger blocking voltage semiconductors tested under rotating operation.

\section{BRIEF THEORETICAL DESCRIPTION OF THE HIGH SPEED BRUSHLESS DE-EXCITATION SYSTEM (HSBDS).}

In this section, the basics of the HSBDS are reviewed. The operation principle of the de-excitation system were described in-depth in [7].

In the event of an internal failure in a synchronous machine, the excitation system must reduce the field current as fast as possible in order to minimize possible damage due to the contribution of the machine to the fault.

In static excitation machines, the existence of brushes allows access to the field winding, and the connection of an additional discharge resistor in the field circuit.

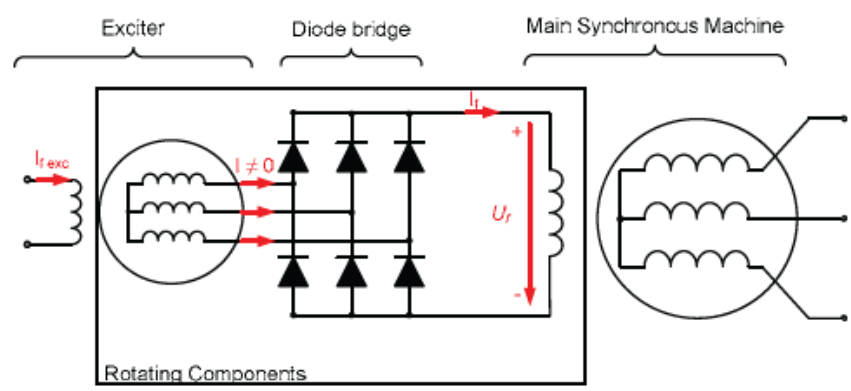

Fig. 1. Brushless Synchronous Machine under normal operation.
In brushless synchronous machines, there is another additional synchronous machine, called the exciter, as shown in Fig. 1. The exciter feeds DC current to the field winding of the main synchronous machine through a rotating diode bridge.

This system does not include brushes, which is a great advantage from a maintenance point of view. However, this implies that the field winding of the main synchronous machine is not accessible. So in the event of an electrical trip, the field is only suppressed through the field winding of the exciter. The main synchronous machine will be deexcited through the rotating diodes, which operate in freewheel mode, close to a short-circuit condition because the voltage drop across the diodes is negligible compared with the rotor voltage (See Fig. 2). So in this type of excitation system the damage would be very severe, even if the electrical protection relays operated correctly, as the short-circuit current supplied by the machine will last several seconds.

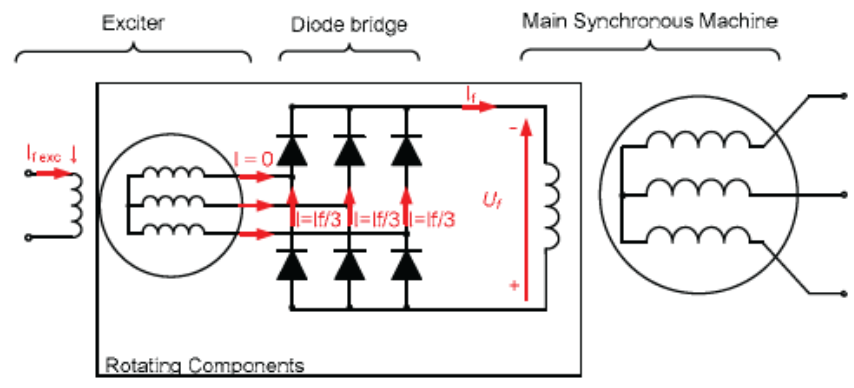

Fig. 2. Brushless Synchronous Machine under de-excitation.

The transient behavior of the synchronous machine is represented by the transient time constant $T_{d^{\prime}}(1)$. It depends on the field winding impedance $\left(\mathrm{R}_{\mathrm{f}}, \mathrm{L}_{\mathrm{f}}\right)$, the rotor-stator coupling $\left(\mathrm{M}_{\mathrm{f}}\right)$ and the stator winding inductance $\left(\mathrm{L}_{\mathrm{d}}\right)$.

The time constant at no-load condition (2) only depends on the field winding impedance. In any case, both time constants are inversely proportional to the field winding resistance.

$$
\begin{aligned}
& T_{d}{ }^{\prime}=\frac{L_{f}-\frac{M_{f}^{2}}{L_{d}}}{R_{f}} \\
& T_{d 0}{ }^{\prime}=\frac{L_{f}}{R_{f}}
\end{aligned}
$$

The typical value of the time constant of a large brushless machine is in the range of 0.5 to 1 second for $T_{d^{\prime}}(1)$ and 5 to 9 seconds for $\mathrm{T}_{\mathrm{d} 0}{ }^{\prime}(2)$. [9]-[10]

The proposed system aims to achieve a transient behavior comparable to that in a brush-fed static-excited machine. It is 
also intended to maintain the advantages and simplicity of brushless machines, by not depending on any additional external signal from the control system, the protection system or the automatic voltage regulator (AVR).

The proposed de-excitation system consists of a discharge resistor, inserted between the rotating diode bridge and the main machine field winding, with a static switch. This switch is controlled through the voltage measured at the diode bridge by a control circuit, thus eliminating the need for an external signal, via either radio, slip rings or special transformers, as in several solutions from different manufacturers [11]-[14].

The excitation system and the automatic voltage regulator scheme would remain the same as in a conventional brushless synchronous machine, and the discharge resistor would be connected only if field suppression were to be required.

A diagram of the proposed de-excitation system is shown in Fig. 3. The components of the system and their connections can be observed: one static switch (semiconductor-based), a control circuit, and a discharge resistor $\left(R_{d}\right)$. The discharge resistor must be dimensioned in order to dissipate the energy stored in the field winding, by considering the insulation voltage of the field winding for the maximum field current.

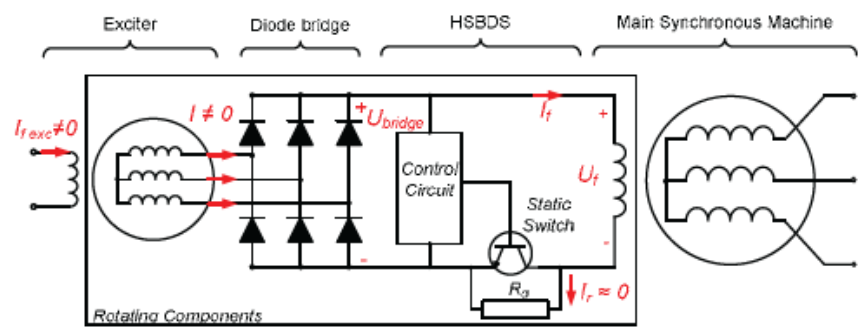

Fig. 3. High Speed Brushless De-excitation System HSBDS during normal operation.

During normal operation of the synchronous machine, a current $\left(\mathrm{I}_{\mathrm{f} \text { exc }}\right)$ flows through the exciter field winding, as shown in Fig. 3. This induces an AC voltage in the armature windings of the exciter and current flows through them, feeding the main synchronous machine field winding with a field current $\left(\mathrm{I}_{\mathrm{f}}\right)$. Consequently, a positive voltage appears at the diode bridge and thus at the field winding $\left(\mathrm{U}_{\mathrm{f}}\right)$. The positive voltage in the diode bridge makes the control circuit trip the static switch, so the current flows mainly through it, and only a small current flows through the discharge resistance due to the voltage drop across the static switch.

In the event of an electrical trip in a brushless synchronous machine, only the exciter field winding current can be reduced quickly, as the rotor of the main machine is not accessible. By decreasing the current in the exciter field winding, the output voltage at the diode bridge drops. Then, a voltage will be induced in the field winding of the main machine with opposite-to-normal polarity, as it is highly inductive. Thus, the current through the winding would not change suddenly, nor would the magnetic flux. The reverse voltage induced in the field winding causes the voltage in the diode bridge to become slightly negative, and the control circuit will turn off the static switch, hence leading the field current to flow through the discharge resistor $\left(R_{d}\right)$, as shown in Fig. 4.

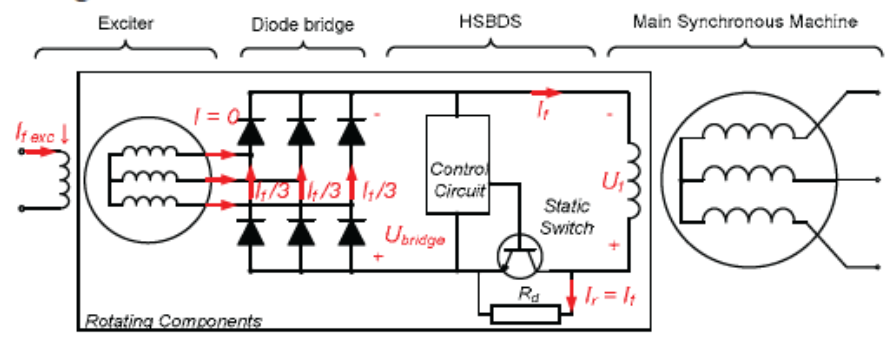

Fig. 4. High Speed Brushless De-excitation System HSBDS during normal de-excitation.

This operating scheme reduces the de-excitation time constant of the main synchronous machine significantly, by adding the discharge resistor in the circuit, as indicated in (3) and (4). The resulting transient response of the brushless machine is made comparable to that of a static excitation machine by dimensioning the discharge resistance adequately.

$$
\begin{aligned}
& T_{d}{ }^{\prime}=\frac{L_{f}-\frac{M_{f}^{2}}{L_{d}}}{R_{f}+R_{d}} \\
& T_{d 0^{\prime}}{ }^{\prime}=\frac{L_{f}}{R_{f}+R_{d}}
\end{aligned}
$$

\section{DESIGN OF HSBDS.}

During the design of the High Speed Brushless Deexcitation System (HSBDS) several point have to be taken into consideration, as:

- Maximum field current during short-circuit.

- Maximum energy to be dissipated in the discharge resistor.

- Maximum rotor overvoltage.

- Maximum static switch overvoltage.

The overvoltage during the de-excitation take place just before the opening of the static switch, according to the circuit shown in the Fig. 5 and the expression (5).

$$
U_{f}=U_{R}+U_{\text {diode }} \approx U_{R}
$$

At that moment the field current raise it maximum value. The overvoltage depends on the field current and the discharge resistor value. (6) 


$$
V_{R}=V_{C E}=I_{f} R_{d}
$$

The maximum overvoltage occurs when the maximum field current flow in the winding, which correspond to the de-excitation some milliseconds after a three-phases shortcircuit. The maximum overvoltage should be limited in order to not damage the field winding insulation and the power semiconductor of the static switch. It is a normal practice to limit the maximum overvoltage below the $80 \%$ of the insulation voltage in order not to damage the winding.

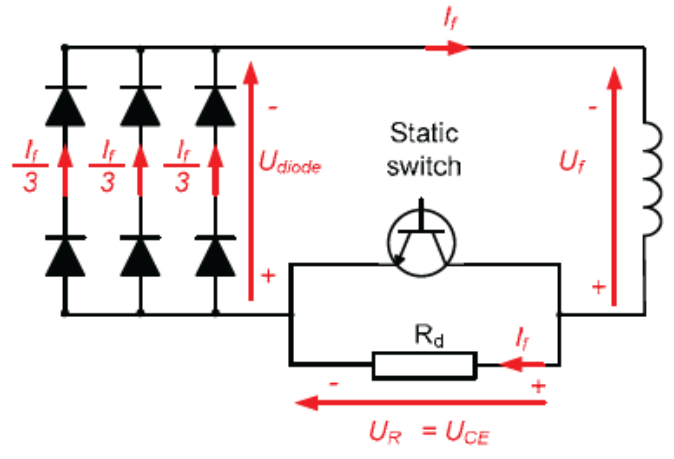

Fig. 5. Equivalent circuit of the High Speed De-excitation System HSBDS during de-excitation.

On the other hand the maximum overvoltage should be limited below the blocking voltage of the semiconductors.

The greater overvoltage, the faster de-excitation process. Therefore the value of the discharge resistor should be carefully selected, to limit the maximum overvoltage having a rapid de-excitation.

In these generators the discharge resistors used are nonlinear resistors [4] of silicon carbide that improves the response compared with a linear resistor. The maximum overvoltages are limited to 400 and $1120 \mathrm{~V}$ respectively for the generator 1 and 2 in which the HSBDS have been tested.

\section{COMMISSIONING OF HSBDS IN A 20 MVA BRUSHLESS GENERATOR OF A HYDRO POWER PLANT.}

The HSBDS was installed in two 20MVA salient pole generators of a Hydro Power Plant.

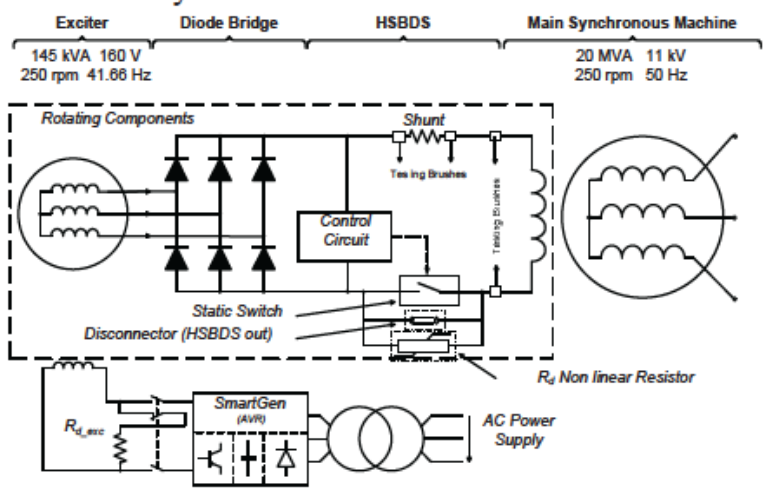

Fig. 6. Simplified scheme of the excitation system of a hydro power plant of 20 MVA where the HSBDS was installed.
The original excitation systems with a DC exciters were changed and substituted by a brushless exciters. The new excitation scheme installed is based on the HSBDS with an AVR SmartGen type, as shown in Fig. 6.

The control circuit measures the voltage of the diodes bridge, so when the voltage is inverted, the static switch is turned off, and the non-linear discharge resistor $\left(R_{d}\right)$ is connected. An exciter discharge resistor $\left(R_{d \text { exc }}\right)$ was installed inside the exciter cabinet to demagnetize the exciter.

The main characteristics of the generator and the exciter are detailed in Table 1 and 2 respectively in the Appendix.

\section{A. Static switch and resistor sizing}

Several commercial semiconductor switches were used as static switch. In order to reach a higher current capacity, several semiconductor were connected in parallel. The semiconductor (1), the discharge resistor (2) and the testing brushes (3) are displayed in Fig. 7.

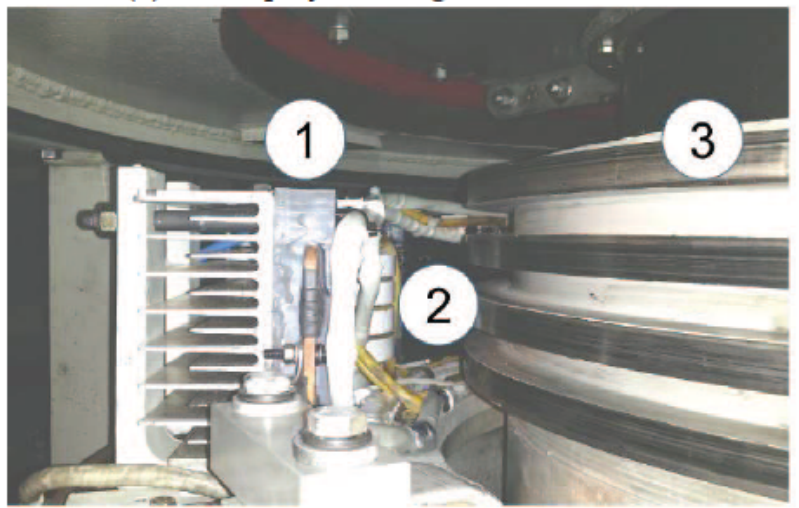

Fig. 7. HSBDS in a 20 MVA hydro generator where 1) Semiconductor 2) Non-linear discharge resistor 3) Brushes for testing.

In each generator, a different type of semiconductor was used, in order to compare their performance:

- Low blocking voltage, $\mathrm{U}_{\mathrm{CE} \max }=400 \mathrm{~V}$

- High blocking voltage, $\mathrm{U}_{\mathrm{CE} \max }=1200 \mathrm{~V}$

With a higher blocking voltage of the semiconductor, a higher resistance (Rd) can be used, getting a lower deexcitation time as checked during the no-load tests.

\section{B. No-load tests}

During these tests the generator operates at full speed, rated voltage and no-load. In this operational condition the exciter field breaker is open. The main generator voltage $\left(\mathrm{U}_{\text {gen }}\right)$ during the de-excitation process is shown in the Fig. 8.

The de-excitation time constant for a conventional brushless excitation is $3.965 \mathrm{~s}$. This test has been performed using the disconnector, so the HSBDS is out of service.

The other tests were performed with the High Speed Brushless De-excitation System in operation. In these cases the semiconductors have a blocking voltage $\left(\mathrm{U}_{\text {CEmax }}\right)$ of $400 \mathrm{~V}$ and $1200 \mathrm{~V}$ respectively, obtaining de-excitation time constant of $1.057 \mathrm{~s}$ and $470 \mathrm{~ms}$.

It can be observed that the de-excitation time constant is reduced, four times, in the first generator while the reduction 
is more than eight times in the second one.

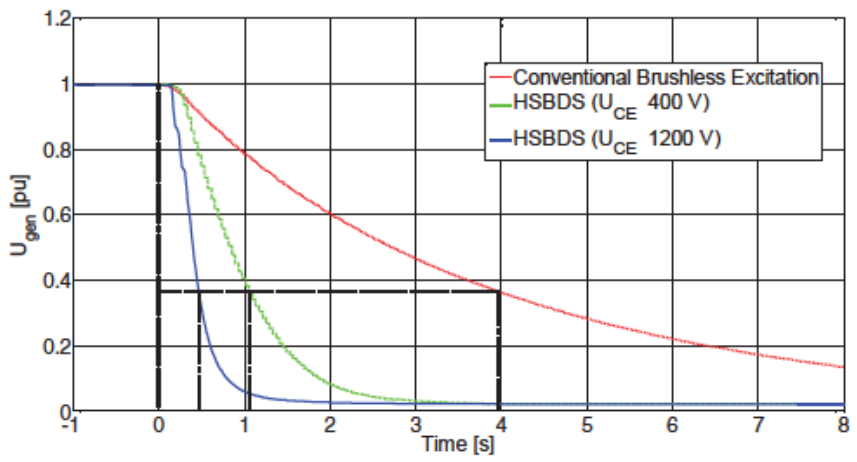

Fig. 8 Generator voltage during the no-load de-excitation tests in 20 MVA hydro generators.

In the Fig. 9 the voltage in the field winding is represented. In the case of a conventional brushless excitation, the rotor voltage decrease to a voltage close to zero, corresponding to the voltage drop in the diodes while operating in freewheel mode.

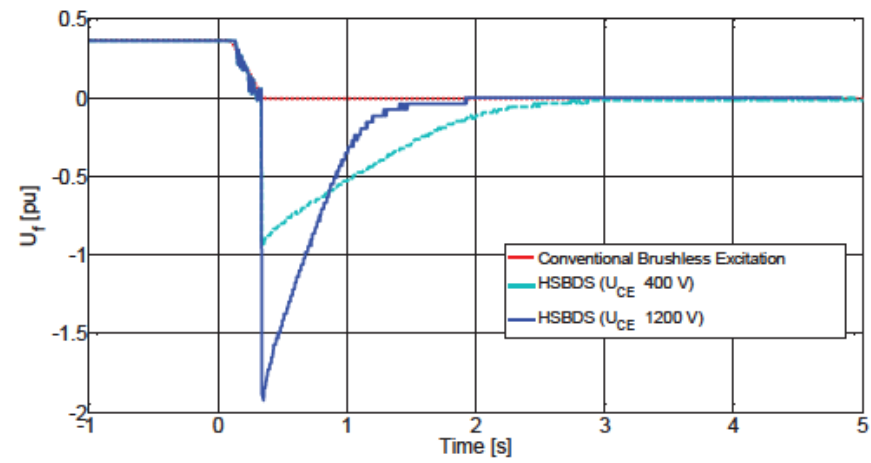

Fig. 9 Generator field voltage during the no-load de-excitation tests in 20 MVA hydro generators.

In case of the HSBDS with semiconductor with $\mathrm{U}_{\mathrm{CEmax}}$ of $400 \mathrm{~V}$, the maximum overvoltage is almost the rated excitation voltage. On the other hand in the case of semiconductors with $\mathrm{U}_{\mathrm{CEmax}}$ of $1200 \mathrm{~V}$, the maximum overvoltage is almost twice the rated excitation voltage.

\section{CONCLUSIONS.}

In the development of the High Speed Brushless Deexcitation System (HSBDS) one of the problem is the rotating operation of the components, especially the semiconductor used as static switch.

The new de-excitation system for brushless synchronous machines has been designed, built, commissioned and tested in two 20 MVA commercial hydro generators.

In the first generator low voltage blocking semiconductors $(400 \mathrm{~V})$ were used as static switch. The de-excitation time constant was reduced from $4 \mathrm{~s}$ to $1 \mathrm{~s}$.

In the second generator the de-excitation time constant was reduced more than eight times in comparison to the same machine with a conventional brushless excitation. This improvement has been obtained thanks to the use of semiconductor with a larger blocking voltage $(1200 \mathrm{~V})$, so it is possible the de-excitation of the field winding quicker as the discharge resistor could be increased.

This second 20 MVA hydro generator has been in commercial operation with the HSBDS for six months, which validate the operation of this type of semiconductor under rotating operation in a large power synchronous generators.

\section{APPENDIX}

TABLE I

MAIN GENERATOR RATINGS

\begin{tabular}{|c|r|}
\hline Manufacturer & $\begin{array}{r}\text { Sécheron } \\
\text { Geneva/Switzerland 1962 }\end{array}$ \\
\hline Type & S24-360-145 \\
\hline Rated apparent power & $20 \mathrm{MVA}$ \\
\hline Rated voltage & $50 \mathrm{kV} \pm 10 \%$ \\
\hline Frequency & $250 \mathrm{rpm}$ \\
\hline Rated speed & 0.85 \\
\hline Rated power factor & $652 \mathrm{~A}$ \\
\hline Rated excitation current & $210 \mathrm{~V}$ \\
\hline Rated excitation voltage & $325 \mathrm{~A}$ \\
\hline No load excitation current & $104 \mathrm{~V}$ \\
\hline No load excitation voltage & \\
\hline $\begin{array}{c}\text { Direct axis reactances } \\
\left(X_{d} / X^{\prime}{ }_{d} / X^{\prime \prime}{ }_{d}\right)\end{array}$ & $133 / 35.5 / 22.4 \%$ \\
\hline $\begin{array}{c}\text { Quatradure axis reactances } \\
\left(X_{q} / X^{\prime \prime}{ }_{q}\right)\end{array}$ & $83.5 / 19.8 \%$ \\
\hline $\begin{array}{c}\text { Time constants } \\
\left(T^{\prime}{ }_{d} / T^{\prime \prime}{ }_{d} / T^{\prime \prime}{ }_{q}\right)\end{array}$ & $0.965 / 0.035 / 0.030 \mathrm{~s}$ \\
\hline
\end{tabular}

TABLE II

EXCITER RATINGS

\begin{tabular}{|c|r|}
\hline Manufacturer & $\begin{array}{r}\text { Alstom Power } \\
\text { Bilbao/Spain 2013 }\end{array}$ \\
\hline Type & WE 11320 20/24 \\
\hline Rated apparent power & $145 \mathrm{kVA}$ \\
\hline Rated voltage & $160 \mathrm{~V}$ \\
\hline Frequency & $41.66 \mathrm{~Hz}$ \\
\hline Rated speed & $250 \mathrm{rpm}$ \\
\hline Rated power factor & 0.96 \\
\hline Rated excitation current & $8.3 \mathrm{~A}$ \\
\hline Rated excitation voltage & $118.9 \mathrm{~V}$ \\
\hline No load excitation current & $4.3 \mathrm{~A}$ \\
\hline No load excitation voltage & $61.6 \mathrm{~V}$ \\
\hline $\begin{array}{c}\text { Direct axis reactances } \\
\left(X_{d} / X^{\prime}{ }_{d} / X^{\prime \prime}{ }_{d}\right)\end{array}$ & $113 / 28.1 / 26.6 \%$ \\
\hline $\begin{array}{c}\text { Quatradure axis reactances } \\
\left(X_{q} / X^{\prime \prime}{ }_{q}\right)\end{array}$ & $71.4 / 58.6 \%$ \\
\hline $\begin{array}{c}\text { Time constants } \\
\left(T^{\prime}{ }_{d} / T^{\prime \prime}{ }_{d} / T^{\prime \prime}{ }_{q}\right)\end{array}$ & $0.285 / 0.024 / 0.031 \mathrm{~s}$ \\
\hline
\end{tabular}




\section{ACKNOWLEDGMENT}

The authors wish to acknowledge the technical support of ALSTOM Renovables SA and ENDESA Generación SA, and especially F. Puigmal, I. Aretxederra, J.R. Diago, M. Alvarez and M. Villarejo.

\section{REFERENCES}

[1] C37.102: "IEEE Guide for AC Generator Protection," IEEE Standard, 2006.

[2] Gaona, C.A.P.; Blázquez, F.; Frías, P.; Redondo, M., "A Novel Rotor Ground-Fault-Detection Technique for Synchronous Machines With Static Excitation," Energy Conversion, IEEE Transactions on, vol.25, no. 4 , pp. 965,973 , Dec. 2010.

[3] M.G. McArdle, D.J. Morrow, "Non-invasive detection of brushless exciter rotating diode failure," IEEE Trans. Energy Convers., vol. 19, no. 2, pp. 378-383, Jun. 2004.

[4] J. Taborda, "Modern technical aspects of Field Discharge equipment for excitation systems", Power and Energy Society General Meeting, Conversion and Delivery of Electrical Energy in the 21st Century, pp. $1-8,2008$.

[5] C. Xianming, W. Wei, L. Hongshui, L. Guohua, Z. Xiaodong, "New Alternating current De-excitation for Large Hydraulic Generators", Joint International Conference on Power System Technology and IEEE Power India Conference, 2008, pp. 1 - 7, 2008

[6] Platero, C.A., Blázquez F., Frías P., Redondo M., Granizo R., Carrero C. "Rapid deexcitation system for synchronous machines with indirect excitation". PCT Patent PCT/ES2010/000058

[7] Platero, C.A.; Redondo, M.; Blázquez, F.; Frías, P., "High-speed deexcitation system for brushless synchronous machines", Electric Power Applications, IET, vol.6, no.3, pp.156, 161, March 2012.

[8] Rebollo-Lopez E., Blanquez-Delgado F., Platero C.A. et Al. "Nuevo Sistema de Desexcitación Rápida para Máquinas Síncronas con Excitación "Brushless" (HSBDS) en un Generador de 15 MVA" Dyna. noviembre 2014. Vol. 89-6 p.642-648.

[9] Kundur, P., Power system Stability and control, Palo Alto, California: McGraw-Hill, 1993, p. 153.

[10] Hu Jiawu, "Analysis of and reflection on the short-circuit fault of a large hydraulic generator," Generation, Transmission \& Distribution, IET, vol.8, no.4, pp.661,669, April 2014

[11] Asea Brown Boveri, Claes Ivarsson "Method and device for demagnetizing brushless synchronous machines," Patent PCT/SE1993/000244 1993.

[12] Westinghouse Electric Corp. D. I. Gorden, P. Munhall, "Fast deexcitation brushless exciter", U.S. Patent 4152 636, 1979.

[13] Schneider, "Entregungsschaltung für bürstenios über rotierende Dionen erregte Synchronmaschinen," German Patent DE 1763299, Oct. 21, 1971.

[14] Siemens, "Anordnung zur Schnellentregung von bürstenlosen Synchronmachinen, die über umlaufende ungesteuerte Gleichrichter erregt werden", German Patent DE 2127497, 1971

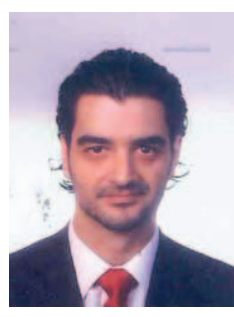

F. Blázquez (M’07) was born in Toledo, Spain in 1972. He received the Dipl. degree in industrial engineering and the Ph.D. degree in electrical engineering from Universidad Politécnica de Madrid, in 1997 and 2004, respectively. Since 1999 he has been professor at the Electrical Engineering Department of the Universidad Politécnica de Madrid. His current research interests include electrical machine design and wind power generation.

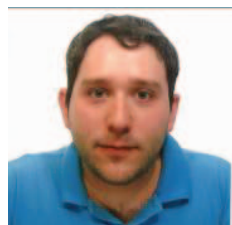

Emilio Rebollo was born in Spain in 1986. He received the Dipl. degree in electrical engineering from the Universidad Politécnica de Madrid in 2010. He's a Ph.D student of the Electrical Engineering Department, Universidad Politécnica de Madrid. His research interests are Electrical machines design and Regulation of Power Plants.

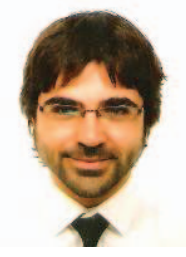

Francisco R. Blánquez was born in Spain in 1986. He received the Dipl. degree in electrical engineering from the Universidad Politécnica de Madrid, Spain, in 2010. He's currently pursuing the $\mathrm{Ph} . \mathrm{D}$ degree in the Division of Electrical Engineering, Universidad Politécnica de Madrid. His research interests include protective relaying of power systems, electrical machine diagnosis and power converters. $\mathrm{He}$ works as project associate in the High-PowerConverters section of Technology Department at CERN (European Organization for Nuclear Research), Geneva, Switzerland.

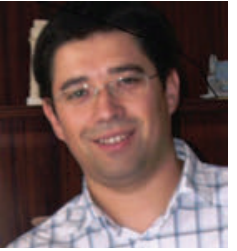

Jose A. Martinez was born in León in 1975. He received his B.Sc. degree in Electrical Engineering and his degree in automation and industrial electronic from Universidad de Pais Vasco (UPV) in 1999 and 2005 respectively. He's working for ALSTOM Renonables España since 2001, in Bilbao Spain. He is responsible for especial $\mathrm{R}+\mathrm{D}$ projects in the Excitation and Auxiliaries Engineering Department.

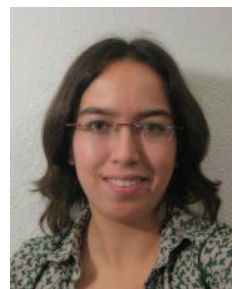

Marta Redondo was born in León, Spain, in 1984 She received her B.Sc. (Hons.) degree in Electrical Engineering from Universidad de León (Spain) in 2005 and Dipl-Eng. (Hons.) degree in Electrical Engineering from Universidad Politécnica Madrid (Spain) in 2007.

She worked for Eselec Ingenieros S.L and she is currently working for ENDESA Generación S.A. and developing her Ph.D. thesis on electrical machines at Universidad Politécnica Madrid. Her research interests include electrical machines, power system protection and wind power generation

\section{AUTHORS' INFORMATION}

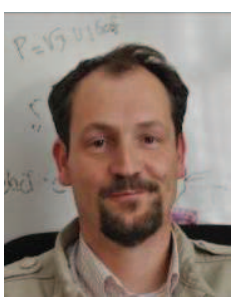

Carlos A. Platero (M'10) was born in Madrid, Spain, in 1972. He obtained the Dipl. degree and $\mathrm{Ph} . \mathrm{D}$. degree in electrical engineering from the Universidad Politécnica de Madrid, Spain, in 1996 and 2007 respectively. Since 1996 to 2008 he has worked in ABB Generación S.A., Alstom Power S.A. and ENDESA Generación SA, always involved in design and commissioning of power plants. In 2002 he began teaching at the Electrical Engineering Department of the Universidad Politécnica de Madrid, and joined an energy research group. Since 2008 he became full-time Associate Professor. 